\title{
Incidence and clinical profile of coronary artery disease in patients with rheumatic heart disease undergoing valvular intervention
}

\author{
Nikhil D Jadhav ${ }^{1}$, Kamal H Sharma ${ }^{1}$, Komal H Shah², Ashwati Konat ${ }^{2}$, Dhammdeep Humane ${ }^{1}$, Sachin Patil ${ }^{1}$ \\ ${ }^{1}$ Department of Cardiology, U. N. Mehta Institute of Cardiology and Research Center, Civil Hospital, Asarwa, \\ Ahmedabad, Gujarat, India. ${ }^{2}$ Department of Research, U. N. Mehta Institute of Cardiology and Research Center, Civil \\ Hospital, Asarwa, Ahmedabad, Gujarat, India.
}

Address for Correspondence: Dr. Nikhil Jadhav, Assistant Professor in Cardiology. U. N. Mehta Institute of Cardiology and Research Center, (Affiliated to B. J. Medical College), New Civil Hospital Campus, Asarwa, Ahmedabad, Gujarat, India. Email: drnikhiljadhav2007@gmail.com.

\begin{abstract}
Background: We aimed to determine the overall prevalence of coronary artery disease (CAD), atherosclerotic risk factors and clinical profile of patients with rheumatic heart disease (RHD) undergoing valvular interventions in Asian Indians. Method: This was an all comers, observational, prospective study of 757 rheumatic patients, who underwent coronary angiography (CAG) prior to percutaneous balloon valvulotomy, surgical valvular repair or replacement from July 2011 to December 2013. Among them who had significant CAD (stenosis $\geq 50 \%$ ) (Group A), were compared with similar number of age and sex matched patients of RHD without CAD (Group B). Result: The overall prevalence of CAD in the patients undergoing valvular intervention was $9.1 \%$ (66.7\% males, $33.3 \%$ female; mean age 55.20 \pm 8.6$)$. The CAD incidence in patients with mitral, aortic and both valve replacement were $24.1 \%, 10.8 \%$ and $6.1 \%$ respectively. The prevalence of smoking habit $(33.3 \%$ vs. $20.9 \%)$, diabetes $(24.6 \%$ vs. $3.1 \%)$, hypertension $(21.7 \%$ vs. $6.8 \%)$, postmenopausal status $(65.2 \%$ vs. $18.4 \%)$, family history of CAD (17.4\% vs. $8.3 \%)$ and aortic valve disease (10.1\%) was significantly higher in group A as compared to group B except for obesity (11.5\% vs. 18.7\%). Conclusion: Prevalence of CAD in patients with valvular heart disease in western population of Asian Indians is 9.1\%. Coronary angiography should be performed in patients having CAD risk factors, irrespective of the valvular lesion involved.
\end{abstract}

Keywords: Rheumatic heart disease, Valvular Interventions, Coronary artery disease, Incidence, Risk factors

\section{Introduction}

Rheumatic heart disease (RHD) - a consequence of rheumatic fever persuaded degenerative changes in the cardiac valve tissue, causes permanent damage to the heart valves [1]. Globally, RHD is affecting around 70 million people whereas the Indian burden of the disease ranges from 0.2 to $1.1 / 1000[2,3]$. In studies performed by Berry [4] and Mathur [5] on urban population of Chandigarh and Agra, RHD prevalence was found to be $1.87 / 1000$ and $1.8 / 1000$ in 5-30 years old subjects respectively. Contrary to the burden of RHD on developed countries, which has come down gradually, it still remains prominent cause of morbidity and mortality in the developing countries of the world [3].

Manuscript received $26^{\text {th }}$ September 2016

Reviewed: $7^{\text {th }}$ October 2016

Author Corrected: $18^{\text {th }}$ October 2016

Accepted for Publication $30^{\text {th }}$ October 2016
Several studies have demonstrated frequent association of RHD with manifested coronary artery disease (CAD) leading to poor prognosis [6]. Henceforth coronary angiogram is usually advocated if there is suspicion of $\mathrm{CAD}$ or after a certain age prior to valvular heart surgeries. According to ACC/AHA guidelines routine preoperative coronary angiography $(\mathrm{CAG})$ in patients with valvular heart disease before valve surgery in men aged $\geq 35$ years, in premenopausal women aged $\geq 35$ years who have coronary risk factors, and in postmenopausal women is advocated $[7,8]$.

The primary aim of present investigation was to estimate the prevalence of coronary atherosclerosis in western state of Gujarat in Asian Indian RHD patients, whereas our secondary aim was to compare the 
demographic and atherosclerotic risk factor profile of patients having valvular disease with $C A D$ and without CAD and identify risk factors for CAD in RHD patients.

\section{Material and Methods}

This was a retroprospective study of 757 valvular patients from Western Indian region, who underwent CAG prior to valvular intervention to confirm the presence of clinically significant lesions. All surgical interventions i.e. percutaneous balloon valvulotomy, surgical valvular repair or replacement were taken in the study from July 2011 to December 2013. Coronary angiography was performed via femoral or radial approach with appropriate catheters.

The degree of coronary artery stenosis was estimated by Quantitative CAG as the obstructed proportion of each vessel, expressed as a percentage of the vessel diameter (if the stenosis was $>50 \%$ it is significant CAD). The patients with CAD (Group A), were compared with patients of RHD without CAD (Group B). None of the patients underwent PCI in view of scheduled valvular open heart surgery and all critical lesions were tackled with grafting simultaneously during valvular surgery. RHD was diagnosed by 2D echocardiographic assessment. As is evident that most of the patients were relatively young. As is evident that most of the patients were relatively young, apart from age, history of rheumatic fever and echocardiographic features life subvalvar pathology and multiple valve involvement were considered to confirm diagnosis of rheumatic etiology. Atrial fibrillation was diagnosed with by clinical and doppler assessment. The study protocol was approved by the Institutional Ethics Committee
(CARDIO / UNMICRC / 29/2013). Patients having inflammatory disorders, associated congenital heart disease, constrictive pericarditis, ischemic mitral regurgitation, bicuspid aortic valve and degenerative aortic valve disease were excluded from the study.

Demographic characteristics were recorded by reviewing the patient medical record file. Family history of $\mathrm{CAD}$ was considered as risk factor if $1^{\text {st }}$ degree relative had CAD ( $<55$ years in males and $<65$ years in females). Typical angina was defined as "the presence of substernal chest pain or discomfort that was provoked by exertion or emotional stress which was relieved by rest where as in atypical angina one may not experience typical symptoms of angina and instead may feel a vague chest discomfort, shortness of breath, fatigue, nausea, back or neck pain or burning indigestion. Hypertension (HTN) and diabetes (DM) were diagnosed according to previous guidelines $[9,10]$.

A low hemoglobin count is generally defined as less than 14 grams of hemoglobin per deciliter (140 grams per litre) of blood for men and less than 12 grams per deciliter (120 grams per litre) for women. A raised creatinine was defined as greater than 1.2 milligrams per deciliter.

Statistical Analysis: Statistical analysis was done using software SPSS v.20. Continuous variables were expressed as Mean $\pm \mathrm{SD}$, whereas categorical variables were defined as percentage. The chi-square test was used for the comparison of proportions and the Student's t test was used for the analysis of the continuous variables. Statistical significance was accepted at the level of $\mathrm{p}<0.05$.

\section{Result}

The study cohort consisted of $349(46.1 \%)$ males and 408 (53.9\%) females with an average age of $49.1 \pm 7.7$ years. Out of 757 RHD patients, 69 patients had significant CAD i.e. Group A (males 66.7\%, mean age of 54.1 \pm 8.3 years, and females $33.3 \%$, mean age of $57.3 \pm 9.0$ years) whereas 688 patients had normal coronaries i.e. group B (males $44 \%$, mean age of $49.3 \pm 7.4$ years, females $56 \%$, mean age of $47.9 \pm 7.1$ years). The overall prevalence of CAD in the patients undergoing valvular intervention was $9.1 \%$. Baseline demographic and clinical data of the study groups are presented in table 1 .

Results revealed that patients of group A (RHD with CAD) were predominantly males (66.7\% vs. 44\%) and older (55.2 \pm 8.6 vs. $48.5 \pm 7.3)$ as compared to group B (RHD without CAD). Increased prevalence of family history of CAD (17.4\%vs. $8.3 \%)$, BMI (24.13 \pm 5 vs $21.6 \pm 3.8)$, HTN (21.7\% vs.6.8\%), DM (24.6\% vs.3.1\%) and postmenopausal status (74\% vs. $28 \%$ ) were observed in patients with CAD as compared to patients without CAD. Clinical symptoms such as angina $(60.9 \%)$ and atrial fibrillation $(50.7 \%)$ was significantly higher in patients with CAD. The greater incidence of atrial fibrillation $(50.7 \%$ vs $17.9 \%$ ) and isolated valve abnormalities (mitral: $51.0 \%$ vs $47.9 \%$; aortic: $10.1 \%$ vs $3.2 \%$ ), anemia $(43.5 \%$ vs $10.2 \%)$ and lower EF $(50.5 \pm 9.8 \%$ vs $54.9 \pm 8 \%)$ was observed in patients of group A as compared to group B, however involvement of both the valve was more common in patients of group B (48.8\% vs $31.8 \%)$. 
Table-1: Demographic data of the study population.

\begin{tabular}{|c|c|c|c|c|c|}
\hline Sr. no & Variable & $\begin{array}{c}\text { Total patients } \\
\text { (757) N \% }\end{array}$ & $\begin{array}{c}\text { Group - A } \\
\text { (69) N\% }\end{array}$ & $\begin{array}{c}\text { Group - B } \\
(688) \text { N\% }\end{array}$ & ${ }^{a}$ p-value \\
\hline 1 & Male & $349(46.1)$ & $46(66.7)$ & $303(44)$ & \multirow[t]{2}{*}{0.0005} \\
\hline 2 & Female & $408(53.9)$ & $23(33.3)$ & $385(56)$ & \\
\hline 3 & Age in years* & $49.1 \pm 7.6$ & $55.2 \pm 8.6$ & $48.6 \pm 7.3$ & $<0.001$ \\
\hline 4 & BMI $(\mathrm{kg} / \mathrm{m} 2)^{*}$ & $21.78 \pm 4.0$ & $24.13 \pm 5.0$ & $21.6 \pm 3.8$ & $<0.0001$ \\
\hline 6 & Smoking & $167(22.1)$ & $23(33.3)$ & $144(20.9)$ & 0.0267 \\
\hline 7 & Family history of CAD & $69(9.1)$ & $12(17.4 \%)$ & $57(8.3)$ & 0.0222 \\
\hline 8 & Angina (typical) & $251(33.2)$ & $32(46.4)$ & $219(31.8)$ & 0.0207 \\
\hline 9 & Angina (atypical) & $35(4.6)$ & $10(14.5)$ & $25(3.6)$ & 0.0001 \\
\hline 10 & Dyspnea & $567(74.9)$ & $57(82.6)$ & $510(74.1)$ & 0.1605 \\
\hline $10 \mathrm{a}$. & NYHA Class I & $17(2.2)$ & $2(2.9)$ & $15(2.2)$ & 0.9663 \\
\hline $10 b$. & NYHA Class II & $423(55.9)$ & $38(55.1)$ & $385(56)$ & 0.9886 \\
\hline $10 \mathrm{c}$. & NYHA Class III & $104(13.7)$ & $17(24.6)$ & $87(12.6)$ & 0.01 \\
\hline $10 \mathrm{~d}$. & NYHA Class IV & $19(2.5)$ & $1(1.4)$ & $18(2.6)$ & 0.8515 \\
\hline 11 & Post-menopausal Status & $122(17.7)$ & $17(74)$ & $107(28)$ & $<0.0001$ \\
\hline \multicolumn{6}{|c|}{ Echocardiographic parameters } \\
\hline 12 & Atrial fibrillation & $158(20.9)$ & $35(50.7)$ & $123(17.9)$ & $<0.0001$ \\
\hline 13 & Mitral valve & $29(3.8)$ & $40(51.0)$ & $330(47.9)$ & 0.0002 \\
\hline 14 & Aortic valve & $370(48.9)$ & $7(10.1)$ & $22(3.2)$ & $<0.0001$ \\
\hline 15 & Both valve & $358(47.3)$ & $22(31.8)$ & $336(48.8)$ & $<0.0001$ \\
\hline 16 & $\begin{array}{l}\text { LVDD on ECHO* } \\
(\mathrm{mm})\end{array}$ & $45.8 \pm 8.0$ & $46.1 \pm 7.9$ & $45.8 \pm 8.0$ & 0.782 \\
\hline 17 & $\begin{array}{l}\text { LVDS on ECHO* } \\
(\mathrm{mm})\end{array}$ & $30.2 \pm 7.7$ & $31.3 \pm 7.6$ & $30.1 \pm 7.6$ & 0.22 \\
\hline 18 & $\mathrm{EF} \%$ on $\mathrm{ECHO}^{*}$ & $54.5 \pm 8.3$ & $50.5 \pm 9.8$ & $54.9 \pm 8.0$ & $<0.0001$ \\
\hline \multicolumn{6}{|c|}{ Clinical variables } \\
\hline 19 & Diabetes & $38(5.0)$ & $17(24.6)$ & $21(3.1)$ & $<0.0001$ \\
\hline 20 & Hypertension & $62(8.2)$ & $15(21.7)$ & $47(6.8)$ & $<0.0001$ \\
\hline 21 & Low hemoglobin & $657(86.8)$ & $30(43.5)$ & $70(10.2)$ & $<0.0001$ \\
\hline 22 & Raised creatinine & $54(7.41)$ & $61(88.4)$ & 642(93.3) & 0.0093 \\
\hline 23 & $\mathrm{ESR}^{*}(\mathrm{~mm})$ & $25.6 \pm 14.9$ & $24.5 \pm 6.1$ & $25.7 \pm 15.5$ & 0.53 \\
\hline
\end{tabular}

Coronary angiography parameters showed that in RHD with CAD group single vessel disease (SVD), double vessel disease (DVD) and triple vessel disease (TVD) was seen in 55.1\%, 29\% and $15.9 \%$ respectively while LMCA (left main coronary artery) was involved in $8.7 \%$ cases. All three vessels were involved in $11.6 \%$ of the patients. In RHD patients, involved vessel were left anterior descending artery (LAD - 57.9\%), left circumflex artery (LCx - 57.9\%) and right coronary artery (RCA - 34.7\%) (Table 2).

The involvement of various valves in both the groups is indicated in table 3 , showing dominance of mitral valve disease in patients with CAD (10.1\%) in comparison to patients without CAD (3.2\%), however the involvement of both valve defect was greater in non CAD patients $(48.8 \%$ vs. $31.8 \%, \mathrm{p}=0.01)$. 
Table-2: Comparison of the coronaries involved.

\begin{tabular}{|c|c|c|}
\hline & & RHD with CAD \\
\hline \multirow{3}{*}{$\begin{array}{c}\text { Coronaries } \\
\text { Involved }\end{array}$} & LAD & $40(57.9 \%)$ \\
\cline { 2 - 3 } & LCX & $40(57.9 \%)$ \\
\cline { 2 - 3 } & RCA & $24(34.7 \%)$ \\
\cline { 2 - 3 } & LAD + LCX & $15(21.7 \%)$ \\
\cline { 2 - 3 } & LAD + RCA & $11(15.9 \%)$ \\
\cline { 2 - 3 } & LCX + RCA & $13(18.8 \%)$ \\
\cline { 2 - 3 } & All three & $8(11.6 \%)$ \\
\hline LMCA & Present & $6(8.7 \%)$ \\
\hline
\end{tabular}

Table-3: Comparison of CAD in various valve diseases.

\begin{tabular}{|c|c|c|c|c|}
\hline & $\begin{array}{c}\text { Mitral valve } \\
\text { N\% }\end{array}$ & $\begin{array}{c}\text { Aortic valve } \\
\text { N\% }\end{array}$ & $\begin{array}{c}\text { Both } \\
\mathbf{N \%}\end{array}$ & p-value \\
\cline { 1 - 3 } $\begin{array}{c}\text { RHD With CAD } \\
(\mathrm{N}=69)\end{array}$ & $7(10.1)$ & $40(57.9)$ & $22(31.8)$ & 0.0015 \\
\cline { 1 - 3 } $\begin{array}{c}\text { RHD With no CAD } \\
(\mathrm{N}=688)\end{array}$ & $22(3.19)$ & $330(47.9)$ & $336(48.8)$ & \\
\hline
\end{tabular}

Table-4: Involvement of various coronaries according to the valvular disease.

\begin{tabular}{|c|c|c|c|}
\hline & Aortic Valve N\% & Mitral Valve N\% & p-value \\
\hline LAD & $25(40.3)$ & $17(58.6)$ & 0.1953 \\
\hline LCx & $26(41.9)$ & $10(34.5)$ & 0.0036 \\
\hline RCA & $12(19.4)$ & $8(27.6)$ & 0.4682 \\
\hline All three & $6(9.7)$ & $4(13.8)$ & 0.7426 \\
\hline
\end{tabular}

The associations of specific coronary artery involvement - lesion at LAD, RCA or LCx with valvular disease are tabulated in table 4. Results revealed that involvement of LCx was significantly $(\mathrm{p}=0.0036)$ higher with aortic valve stenosis as compared to mitral stenosis. All other coronary lesions were equally found in both the groups.

\section{Discussion}

The data evaluating prevalence of angiographically apparent coronary stenosis in RHD patients shows great degree of variation, from $8-50 \%$ [11-14]. In western countries the prevalence was reported to range from 16$50 \%$, whereas in South East Asian countries the reported incidence was ranging from 8\%-31.3\% respectively $[15,16]$. From India, Jose et al., had shown overall prevalence of CAD with RHD as $12.2 \%$ which documented much lower prevalence than the earlier noted western reports[17]. Although the incidence of $\mathrm{CAD}$ is higher among south East Asians and are afflicted at an early age as compared to the western population, the prevalence of CAD in RHD is patients is comparatively low $[18,19,20]$. In the line of this, the current study also shows only $9.11 \%$ incidence of arterial stenosis in valvular patients of western India. This may be due to higher age group in the western countries and partly due to the demographic, clinical and environmental characteristics of the different population like race, dietary habits and physical activity. The ratio of male to female $(2: 1)$ obtained by us was comparable with others showing the ratios from 1.6:1 to $2.6: 1$ [21]. One study from China conveyed the ratio of $3: 1$, further suggesting the higher susceptibility of male gender $[15,21]$. In the present study, mean age of patients having CAD with RHD was $55.2 \pm 8.65$ years which is lower than the mean age of atherosclerotic CAD in India (57.5 years) [22]. The average age of patient having RHD with CAD was around 55-60 years in western and Chinese population which was comparable to Indian and Pakistani studies also $[14,21,23]$. The SVD, DVD or TVD was present in $55.1 \%, 29 \%$ and $15.9 \%$ respectively. Left anterior descending was the most common vessel involved (overall $63.7 \%$ and $30.4 \%$ in isolated cases) followed by LCX $(51 \%)$ and RCA $(35.7 \%)$. Rangel et al and Li $\mathrm{BL}$ et also found that LAD was the most commonly involved artery followed by RCA and LCX [15]. 
Coronary artery disease with RHD is a multifactorial condition involving several risk factors namely smoking, DM, family history of CAD, post-menopausal state and obesity contributing to its pathophysiology. A prospective study, conducted by Jose et al [17] had also reported the higher predictivity of CAD risk factors in rheumatic valve patients using multimarker strategy.

Atalar et al, assessed predictors of CAD in RHD patients on large cohort of 1075 patients and found that HTN, smoking, DM and dyslipidemia are significantly higher in RHD patients with CAD as compared to patients without CAD [24]. The prevalence of CAD in the two models described by Lin et al and Lim et al, was $19.3 \%$ and $36 \%$ respectively [19,25]. It indicates that in patients with RHD, the incidence of CAD was low and thus the strength of prediction and respective relationship between predictors derived in previous analyses might be lost. Presence of angina was significantly more common in the RHD with CAD group than the RHD patients without CAD ( $p=0.0001$ ). Other studies also found that presence of angina is a good predictor of the CAD in RHD patients [12,22, 23].

In our study, a low prevalence of significant CAD of $9.1 \%$ in the rheumatic patients was present, as observed by other investigators [17, 22, 26]. Single Vessel disease was more commonly seen in the other studies also [27]. The reason cannot be the rheumatic-feverpreventing intramuscular antibiotics which could have a protective anti-inflammatory effect on the genesis of coronary atherosclerosis because the patients in our study seldom received such prophylaxis. Kruczan et al. inferred that the low prevalence could be due to the demographic and clinical characteristics [22]. So the above discussion states that, occurrence of CAD may be partly attributed to the presence of multiple risk factors, which holds therapeutic and prognostic significance of diagnosing CAD incidence in valvular patients.

\section{Conclusion}

Prevalence of CAD in patients undergoing intervention for valvular heart disease in Indians is $9.1 \%$. Presence of typical angina was predictive of CAD unlike many other studies in patients of RHD. Coronary angiography should be performed in patients having CAD risk factors who are undergoing for valvular surgery.

Conflict of interest: The authors declare that there is no conflict of interest exist.

\section{List of Abbreviations}

BMI: Body Mass Index; CAD: Coronary Artery disease; NYHA: New York Heart Association; AF: Atrial Fibrillation; LVDD: Left Ventricular Diastolic Dysfunction; LVDS: Left Ventricular Systolic Dysfunction; ECHO: Echocardiography; EF: Ejection Fraction; ESR: Erythrocyte Sedimentation Rate; * expressed as mean \pm standard deviation, RHD: Rheumatic Heart Disease; CAD: Coronary Artery Disease; LAD: Left Anterior Descending; LCx: Left Circumflex; RCA: Right Coronary Artery.

\section{Funding: Nil, Conflict of interest: None. Permission of IRB: Yes}

\section{References}

1. Kumar V, Abbas AK, Fausto N, Aster JC. Robbins and Cotran Pathologic Basis of Disease, Professional Edition: Expert Consult-Online: Elsevier Health Sciences 2009.

2. Mendis S, Puska P, Norrving B. Global atlas on cardiovascular disease prevention and control: World Health Organization 2011.

3. Kumar RK, Tandon R. Rheumatic fever \& rheumatic heart disease: the last 50 years. Indian J Med Res. 2013 Apr;137(4):643-58.

4. Berry JN. Prevalence survey for chronic rheumatic heart disease and rheumatic fever in northern India. $\mathrm{Br}$ Heart J. 1972 Feb;34(2):143-9.

5. Mathur K. Problem of heart disease in India. Am J Cardiol. Jan 1960; 5(1):60-5.

6. Coleman EH, Soloff LA. Incidence of significant coronary artery disease in rheumatic valvular heart disease. Am J Cardiol. 1970 Apr;25(4):401-4.

7. Bonow RO, Carabello BA, Chatterjee K, de Leon AC Jr, Faxon DP, Freed MD et al. ACC/AHA 2006 guidelines for the management of patients with valvular heart disease: A report of the American College of Cardiology/AHA Task Force on Practice guidelines. $J$ Am Coll Cardiol. 2006; 48(3):e1-148.

8. Bonchek LI, Anderson RP, Rösch J. Should coronary arteriography be performed routinely before valve replacement? Am J Cardiol. 1973; 31(4):462-6.

9. Indian Guidelines Management of Hypertension 2001. Hypertension India 2001; 15(2): 1-34.

10. Sahay API-ICP Guidelines on Diabetes. J Assoc Physicians India 2007; 55:1-50. 
11. Chun PK, Gertz E, Davia JE, Cheitlin MD. Coronary atherosclerosis in mitral stenosis. Chest. 1982 Jan;81(1):36-41.

12. Baxter RH, Reid JM, McGuiness JB, Stevenson JG. Relation of angina to coronary artery disease in mitral and in aortic valve disease. Br Heart J. 1978 Aug; 40(8):918-22.

13. Sonmez K, Gencbay M, Akcay A, Yilmaz A, Pala $\mathrm{S}$, Onat $\mathrm{O}$, et al. Prevalence and predictors of significant coronary artery disease in Turkish patients who undergo heart valve surgery. J Heart Valve Dis. May 2002; 11(3):431-37.

14. Bozbaş H, Yildirir A, Küçük MA, Ozgül A, Atar I, Sezgin A, et al. Prevalence of coronary artery disease in patients undergoing valvular operation due to rheumatic involvement. Anadolu Kardiyol Derg.2004;4(3):223-26.

15. Li B, Li L, Hou X, He B, Zhang G, Chen K, et al. Prevalence of coronary artery disease in patients with rheumatic heart disease in China. Zhonghua Yi Xue Za Zhi. 2007; 87(47):3313-16.

16. Shaikh AH, Hanif B, Hasan K, Adil A, Hashmani S, Raza M, Qazi HA, Mujtaba I. Coronary artery disease in patients undergoing valve replacement at a tertiary care cardiac centre. J Pak Med Assoc. 2011 Apr; 61(4):340-2.

17. Jose VJ, Gupta SN, Joseph G, Chandy ST, George OK, Pati PK, John B, George P. Prevalence of coronary artery disease in patients with rheumatic heart disease in the current era. Indian Heart J. 2004 Mar-Apr;56 (2):129-31.

18. Sharma M, Ganguly NK. Premature coronary artery disease in Indians and its associated risk factors. Vasc Health Risk Manag. 2005;1(3):217-25.

19. Lin SS, Lauer MS, Asher CR, Cosgrove DM, Blackstone E, Thomas JD, Garcia MJ. Prediction of coronary artery disease in patients undergoing operations for mitral valve degeneration. J Thorac Cardiovasc Surg. 2001 May;121(5):894-901.
20. Bozbaş H, Yildirir A, Küçük MA, Ozgül A, Atar I, Sezgin A, et al. Prevalence of coronary artery disease in patients undergoing valvular operation due to rheumatic involvement. Anadolu Kardiyol Derg. 2004; 4 (3):223-26.

21. Rangel A, Hernández J, Iris JM, Baduí E, Chávez E. [Indications for coronarography in heart valve diseases]. Arch Inst Cardiol Mex. 1996 Jan-Feb;66(1):60-9.

22. Kruczan DD, Silva NA, Pereira Bde B, Romão VA, Correa Filho WB, Morales FE. Coronary artery disease in patients with rheumatic and non-rheumatic valvular heart disease treated at a public hospital in Rio de Janeiro. Arq Bras Cardiol. 2008; 90(3):217-23.

23. Vandeplas A, Willems JL, Piessens J, De Geest $H$. Frequency of angina pectoris and coronary artery disease in severe isolated valvular aortic stenosis. Am J Cardiol. 1988 Jul 1;62(1):117-20.

24. Atalar E, Yorgun H, Canpolat U, Sunman H, Kepez A, Kocabaş U, et al. Prevalence of coronary artery disease before valvular surgery in patients with rheumatic valvular disease. Coron Artery Dis. Dec 2012; 23(8):533-37.

25. Lim E, Ali ZA, Barlow CW, Jackson $\mathrm{CH}$, Hosseinpour A-R, Halstead JC, et al. A simple model to predict coronary disease in patients undergoing operation for mitral regurgitation. Ann Thorac Surg. Jun 2003; 75(6):1820-25.

26. Guray Y, Guray U, Yilmaz MB, Mecit B, Kisacik H, Korkmaz S. Prevalence of angiographically significant coronary artery disease in patients with rheumatic mitral stenosis. Acta Cardiol. June 2004; 59 (3):305-9.

27. Narang R, Chadha DS, Goel K, Mishra S, Bajaj N, Sharma $S$, et al. Screening coronary angiography prior to surgery in rheumatic valvular heart disease: a study of 2,188 patients. J Heart Valve Dis. Jul 2009; 18(4):455-60.

\section{How to cite this article?}

Nikhil D Jadhav, Kamal H Sharma, Komal H Shah, Ashwati Konat, Dhammdeep Humane, Sachin Patil. Incidence and clinical profile of coronary artery disease in patients with rheumatic heart disease undergoing valvular intervention. Int $J$ Med Res Rev 2016;4(10):1915-1920.doi:10.17511/ijmrr. 2016.i10.31. 